\title{
O uso social da leitura por meio de textos informativos
}

\author{
The social use of reading through informative \\ texts
}

\section{L'utilisation sociale de la lecture au moyen de textes informatifs}

\author{
Maria do Socorro VASCONCELOS
}

\begin{abstract}
RESUMO
"Que sentido òs textos informativos têm para os neoleitores egressos do AlfaSol?" é um projeto de pesquisa-ação que tem por objetivo exercitar a leitura dos adultos recém-alfabetizados em situações concretas da vida cotidiana. O projeto se apóia em consultas bibliográficas e realização de oficinas de leitura na Comunidade do Dendê, utilizando material informativo sobre integração social, exercício da cidadania, cuidados com a saúde, conservação do meio ambiente e melhoria da qualidade de vida das pessoas. Atende a necessidades específicas da população, segundo a Lei de Responsabilidade Social que levou as empresas privadas a atuarem em parceria com o Estado. Foram realizadas visitas à Comunidade do Dendê e feitos contatos com os líderes locais. Essas visitas tinham por objetivo apresentar e discutir com os líderes a viabilidade do projeto e selecionar o local mais adequado para funcionamento das oficinas de leitura. As pessoas da Comunidade do Dendê vêm recebendo uma grande cóntribuição no sentido de-aperfeiçoar as téenieas de leitura, interpretar textos com informações úteis, criar o hábito de ler entre os adultos egressos dos programas de alfabetização, ler conjuntamente com os familiares, amigos e vizinhos, exercitando-se todos para uma convivência harmônica e solidária, em busca de soluções aos problemas atuais que afetam toda a coletividade.
\end{abstract}

Palavras-chave: texto, leitura, neoleitores.

\begin{abstract}
"What kind of meaning do the informative texts bring to the AlfaSol neo-readers?" It's an action-research project which aims to practice the new literates' reading skills through real daily life situations. The project is based on bibliographic research and the development of workshops in
\end{abstract}


reading in the Community of Dendê using texts on social integration, citizenry practice, health care, environment protection and improvement of people's life quality. The project focuses on the community's needs, according to the Law of Social Responsibility which led partnerships between private enterprises and the state government. Visits to the Community of the Dendê had been carried and contacts made with the local leaders. These visits had for objective to present and to argue with the leaders about the viability of the project and to select the place most adequate for the functioning the reading workshops. The people of the Community of Dendê is receiving a great contribution in the direction to perfect the reading techniques, to interpret texts with useful information, to create the habit to read with adult egresses of the literacy programs, to read jointly with familiar, the friends and neighbors, being exercised themselves all for a harmonic and solidarity life, in brainstorming to the current problems that affect all the collective.

Index terms: text, reading, neo-readers.

\section{RÉSUMÉ}

«Que senti les textes informatifs ont pour neolécteurs sorties de l'AlfaSol?» c'est un projet de recherche- action qui a l'objectif d'exercer la lecture des adultes récent-alphabétisés dans des situations concrètes de la vie quotidienne. Le projet si basé à des consultations bibliographiques et à réalisation d'ateliers de lecture dans la Communauté du Dendê, en utilisant matériel informatif sur l'intégration sociale, l'exercice de la citoyenneté,' des soins avec la santé, la conservation de l'environnement et l'amélioration de la qualité de vie des personnes. Il fait attention à des nécessités spécifiques de la population, selon la Loi de Responsabilité Sociale qui a amené les sociétés privées à agir dans partenariat avec l'État. Des visites à la Communauté du Dendê ont été réalisées et des contacts avec les chefs locaux ont été faits. Ces visites avaient l'objectif de présenter et discuter avec les chefs la viabilité du projet et sélectionner le lieu le plus approprié pour le fonctionnement des ateliers de lecture. Les personnes de la Communauté du Dendê viennent en recevant une grande contribution dans le but de perfectionner les techniques de lecture, interpréter des textes avec des informations utiles, créer l'habitude de lire avec les adultes sorties des programmes d'alphabétisation, lire communément avec les parents, amis et voisins, en s'exerçant tous pour une convive harmonique et solidaire, à la recherche de solutions aux problèmes actuels qui touchent toute la collectivité.

Mots clés: texte, lecture, neolécteurs. 


\section{Introdução}

O projeto de pesquisa-ação "Que sentido os textos informativos têm para os neoleitores egressos do Programa de Alfabetização Solidária?" está em fase de realização na Comunidade do Dendê com o objetivo de aperfeiçoar nos neoleitores a técnica de ler para que estes façam uso social da leitura em situações da vida cotidiana.

Seu marco referencial tem por base a pesquisa bibliográfica sobre responsabilidade social das empresas e uso social da leitura em um mundo globalizado, o qual evidencia um cenário de transição de conceitos e valores, enfocando a ação e revela a face do capitalismo atual. Antes, havia uma demarcação bem acentuada das competências dos setores público e privado. Hoje, com a vigência da Lei de Responsabilidade Social, as empresas privadas passaram a atuar em áreas que antes era de competência exclusiva do Estado. "Atualmente, dada a relevância do tema, a responsabilidade social deixou de ser uma opção para tornar-se fator estratégico da política das empresas" (LEVY, et al., 2005, p.15).

As empresas agem de maneira estratégica, traçando metas para atender às necessidades sociais e aos seus próprios interesses. As parcerias entre empresas privadas e instituições governamentais ganham força na aplicação de normas compartilhadas pela sociedade no uso social da leitura e no processo de tomada de decisões, tendo em vista a melhoria da qualidade de vida.

No presente trabalho, definimos como uso social da leitura, as informações que o leitor adquire de forma contínua, através de material impresso e as utiliza no seu dia-a-dia. O contato com o mundo letrado impõe às pessoas a necessidade de dominar o código lingüístico predominante em seu meio social. Mas, a leitura não se limita apenas a fornecer informações úteis, ela também forma a consciência crítica do leitor para conhecer a realidade concreta em que vive. Segundo Paulo Freire, "a 
leitura do mundo precede a leitura da palavra [...] A compreensão do texto a ser alcançada por sua leitura crítica implica a percepção das relações entre o texto e o contexto" (1997, p. 11).

A leitura é um dos meios mais seguros de se obter informação e conhecimentos, de forma permanente. As pessoas de baixo poder aquisitivo, na sua maioria, ficam à margem do conhecimento da leitura e da escrita, por isto desconhecem informações úteis que podem melhorar seus hábitos em quanto cuidar da saúde, saber quais são seus direitos e deveres, comunicarse à distância por meio de carta ou bilhetes. De modo geral, obtêm informações através do rádio, da TV, do telefone, mas não têm o hábito de ler jornais, revistas, livros, panfletos e outros materiais impressos.

\section{Metodologia de trabalho}

Foram realizadas visitas à Comunidade do Dendê e feitos contatos com os líderes locais. Essas visitas tinham por objetivo apresentar e discutì com os líderes a viabilidade do projeto e selecionar o local mais adequado para funcionamento das oficinas de leitura. Optou-se pela Sede do Conselhó Comunitário de Ação Social por apresentar condições mais adequadas ao trabalho, tanto pela localização como pelas condições físicas. Na primeira reunião, fôram apresentados aøs participantes, os objetivos do projeto e os resultados que se esperam obter por meio do uso social da leitura.

Trabalhamos com textos informativos sobre prevenção e cuidados com a saúde, com o meio ambiente, cidadania - envolvendo direitos e deveres dos cidadãos, cultura, lazer e outros de interesse do grupo. Em cada oficina de leitura, é apresentado um banner, contendo o texto selecionado com a participação dos neoleitores. Em seguida, é feita uma leitura individual do texto, em voz alta, obedecendo às normas de pontuação e dicção, para que não haja dúvidas quanto ao processo de interpretação, 
reflexão e discussão do tema. A leitura seguinte é feita em conjunto com o grupo.

Abre-se o debate sobre o tema. Os termos desconhecidos são explicados, por meio de exemplos extraídos do contexto em que vivem os neoleitores, para que a mensagem transmitida seja bem compreendida e eles possam fazer analogias entre o texto e sua própria realidade. Cada participante expressa seu ponto de vista, dizendo como entendeu a mensagem do texto e o que lhe pareceu mais interessante. Após o debate, é pedido aos participantes que destaquem termos ou expressão que mais o impressionaram. Um, de cada vez, levanta-se e vai até o banner grifar no texto o que lhe chamou atenção. Logo em seguida, faz-se a transcrição para a lousa dos trechos grifados. A maioria dos textos utilizados é extraída de panfletos produzidos por instituições que trabalham com saúde, educação, meio-ambiente, cidadania, etc. Quando são utilizados textos diferentes como poesia, conto, lenda ou outro gênero literário, são feitos comentários sobre os respectivos autores, seus gêneros literários e o objetivo das mensagens que pretendem transmitir.

Em outras sessões de leitura utilizam-se dinâmicas diferentes: Os neoleitores escrevem numa folha de papel em branco algo que os interessa. Depois as folhas são recolhidas e a produção deles (palavras, frases, desenhos, sinais) é escrita na lousa, fazendo-se em seguida uma leitura coletiva acompanhada de novo debate e/ou comentários individuais.

Para tornar as oficinas mais interessantes e atrativas, utilizam-se dinâmicas metodológicas diversificadas. Os participantes escrevem na lousa, em folhas de papel ou em tiras de cartolina. Quando usa as tiras de papel, cada um lê em voz alta o que escreveu e em seguida troca sua tira com seu vizinho, que por sua vez lê o que tem escrito na tira de papel e os dois comentam sobre o que escreveram.

Após essa dinâmica, o texto é reescrito. Cada um diz o que entendeu, o que gostou e que não gostou e o porquê. À medida que eles vão 
falando, a professora-pesquisadora assessorada por uma aluna bolsista de iniciação científica vai reescrevendo o texto na lousa. Depois lê o texto reconstruído. Ato contínuo é feita uma leitura individual e depois uma leitura coletiva.

Cópias do texto original são distribuídas com os participantes para que eles releiam em casa, comentem com os vizinhos, amigos, parentes e dêem a outras pessoas da Comunidade para que leiam também. Na sessão seguinte, cada participante recebe cópia do texto reconstruído. São tecidos comentários positivos com o propósito de motivá-los a seguir exercitando a leitura e a produção de textos.

\section{Análise de dados/ resultados}

A Sala de Leitura, adotando a metodologia de leitura partindo do texto, foi inaugurada no dia 8 de março de 2007, Dia Internacional da Mulher. As atividades pedagógicas tiveram início com a leitura das poesiàs "Ser Mulher", de autoria de Gilka Machado e "08 de Março - Dia Internacional da Mulher", da autora Ilsa da Luz Barbosa, estudadas em sessões diferentes, cada uma com duração de uma hora e meia. Funciona uma vez por semana, no turno da noite, de 18:30 às 20:00 horas.

Os demais-temas selecionados têm relação com as necessidades de informação dos participantes. Tratam de como prevenir a saúde, cuidados com as pessoas enfermas, como deve ser feita a higiene do corpo, dos alimentos, do ambiente e, principalmente da água. Também são estudados outros temas sobre cidadania, cultura, lazer etc.

Discutidos e interpretados os textos, destacam-se os aspectos que mais chamam a atenção dos participantes. Esses aspectos podem estar representados por expressões, termos, ou situações da vida cotidiana. Não são palavras isoladas, são termos extraídos do texto que têm a força de temas por traduzirem as necessidades básicas do ser humano, dentro do 
contexto atual em que vive a sociedade brasileira. Esses temas são, por exemplo: segurança e liberdade, que levam o grupo a refletir sobre a insegurança em que se vive nos dias atuais. Inevitavelmente, essas questões trazem consigo situações de insegurança e opressão. A liberdade, mesmo sendo um direito do ser humano, é regida por normas legais e sociais que impõem certos limites no modo de agir, para que exista respeito entre as pessoas e seja possível uma convivência social harmônica. Já a segurança evoca a questão da violência que pode ser física, moral e estrutural. $\mathrm{Na}$ sociedade atual, as pessoas se sentem acuadas com medo da violência praticada nas ruas, tais como: agressões físicas, homicídios, assaltos, furtos, vingança, seqüestros, extermínios, e tambếm a violência doméstica ou familiar praticada no próprio lar contra crianças e mulheres pelos pais, padrasto, marido, namorado, companheiro ou ex-companheiro, etc. Existe também a violência estrutural ou simbólica que é representada pela falta de cumprimento do dever por parte do Estado e/ou displicência de instituiçães públicas e privadas no atendimento aos serviços pagos pelos cidadãos, gerando um clima de tensão e insegurança em todos os setores que induzem à violência moral, a qual é entendida, neste trabalho, como a falta de respeito às pessoas, insultos, calúnias, difamação, negação de seus direitos etc, independentemente da classe social, idade, raça, ideologia política e religião.

O ponto culminante da discussão foi a compreensão de que segurança e liberdade não estão relacionadas somente com a ação policial, mas envolve outros aspectos da vida humana: trabalho, saúde, educação e o atendimento a outras necessidades do ser humano.

O termo Cidadania, quando entrou na discussão deixou de ser apenas uma palavra, mas um tema de debate sobre o verdadeiro sentido do que é ser cidadão. Para o grupo ficou claro que ser cidadão não é apenas tirar documentos, é muito mais que isto. É cumprir com seus deveres e respeitar os direitos dos outros. É viver em sociedade contribuindo para o bem 
comum, é participar do desenvolvimento da Comunidade e tomar decisões coletivas. Nessa discussão foram destacados a participação e o individualismo como termos antagônicos, chegando-se ao consenso de que a pessoa que participa não fica presa ao individualismo, pensando somente na solução de seus problemas, pensa de forma coletiva na solução dos problemas do grupo ou da comunidade.

A questão do preconceito social foi analisada sob as diversas formas de discriminação, envolvendo em primeiro lugar a mulher, estendendo-se à idade, raça, classe social, profissão, portadores de necessidades especiais e outros. A mulher vem lutando, através do movimento feminista e de sua participação em outros movimentos sociais pela conquista de seus direitos, pelo reconhecimento e respeito ao espaço que ela ocupa na sociedade.

$\mathrm{Na}$ discussão sobre o texto em estudo, o termo buscar teve a conotação de decisão, de dinâmica e de perseverança na luta por uma sociedade mais igualitária, mais justa, menos egoísta, menos violenta e mais humana. A mulher, nesse contexto, se revela com a força que sempre esteve latente dentro de si. Se ela tem o poder de gerar e nutrir a vida dentro de si, este poder eclodirá com mais força quando se trata de defender a si mesma numa sociedade que há séculos vem disciplinando o gênero feminine por meio de uma educação repressora, castradora fundamentada na discriminação e no machismo, os quais tentam subestimar o seu potencial criador em defesa da vida, da família, da educação, do amor, da compreensão, do afeto, da profissão, do trabalho e da paz social.

A sociedade atual vê a mulher como objeto sexual e de propaganda comercial, como se ela fosse apenas uma máquina humana de fabricar prazeres. Dentro dessa visão equivocada e excludente, são criados os estereótipos de beleza feminina, quanto ao aspecto física, vestuário, linguagem, moda em geral e outras formas de manipulação e controle que desvirtuam o verdadeiro papel social da mulher. 
O movimento das mulheres é considerado como a corrente cultural mais criadora e revolucionária de nossa época (Cf. ALAMBERT, 2004). Isto nos dá a certeza de que nenhuma sociedade subsistirá sem o potencial criador da mulher.

Aspiração e sonho, dentro do contexto das poesias estudadas como textos introdutórios, denotam a necessidade de se ter uma atitude positiva diante do mundo. Ter disposição e esperança para lutar pelas coisas que queremos conseguir na vida. Ter um ideal que dê sentido à existência temporal. A expressão amar e ser compreendida tocou fundo na sensibilidade dos neoleitores, evidenciando o lado afetivo da mulher e sua docilidade para conduzir as questões domésticas e humanitárias. Seu maior poder reside na afetividade e no carinho ao assumir o carisma de ser mulher e exercer com responsabilidade e compromisso sua missão de mãe, de esposa e de profissional. São três funções, de modo geral integradãs, que representam a prova de fogo da mulher moderna. São três jornadas diấrias de trabalho: duas no emprego e uma na casa ao lado da família, como administradora do serviço doméstico, como educadora dos filhos e comó companheira do marido. A maioria das mulheres tem uma jornada de trabalho, de tempo integral para melhorar a renda familiar. Ocupam os três turnos - manhãa, tarde e noite. Não será esse potencial inigualável da mulher que humilha os homens, gerando neles inveja, discriminação, violência e desrespeito para com o gênero feminino?

No contexto poético, os termos companheiro e senhor têm uma repercussão ambígua: a mulher, na qualidade de fêmea necessita de um companheiro para procriar e viver com ela, compartilhando de suas alegrias e tristezas, de suas vitórias e derrotas. Mas, em muitos casos, o que a experiência tem mostrado é a frustração desse sonho. Um índice elevado de mulheres, em vez de ter ao seu lado, na pessoa de marido, um companheiro, um amigo, um irmão, tem sim, um senhor, um mandatário, um opressor, que 
além de sugar sua energia, tira-lhe também todas as oportunidades para crescer e para realizar seu ideal como mulher.

No estudo do tema "Doação de órgãos", o material de leitura utilizado orienta sobre as condições dos doadores e que tipo de órgãos podem ser cedidos por pessoas vivas e por cadáveres, despertando muito interesse nos participantes. A discussão culminou com a construção do seguinte texto: Doar o coração é importante para reviver outra vida. A doação é importante porque nos faz felizes em compartilhar a saúde com outras pessoas. Se as pessoas tivessem a compreensão de doar órgãos, muitas vidas eram salvas. Doar é compartilhar a vida com outras pessoas necessitadas. É um ato de solidariedade humana.

O texto original foi bem assimilado, oferecendo informações que contribuem para uma formação humana preocupada com o bem estar das outras pessoas e solidariedade com os que necessitam de ajuda.

O tema trabalhado em outra oficina foi "Hipertensão arterial ou pressão alta". Os participantes contribuem com outras informações sobre cuidados com a saúde, chás que curam e higiene corporal. Um senhor pediu a palavra e disse: Eu já fui garçon e o gerente ensinou que quando a gente fosse tomar banho, a gente passasse o sabão de coco nas pernas e nos braços de baixo para cima, deixar secar um pouco e depois enxágua.

Perguntamos o porquê. Ele respondeu: Porque passamos o dia inteiro em pé.

Essa resposta deixou subentendido que a orientação do gerente era uma medida para melhorar a circulação. Outras pessoas interagiram no debate e uma senhora disse: Fazia três meses que estava com uma hemorragia, já tinha tomado tudo e não parava, aí me disseram que eu tomasse chá da folha da castanholeira. Fiz o chá, tomei só duas vezes e fiquei boa.

Outra pessoa falou que o chá da casca da romã também serve para curar hemorragia. 
Como podemos observar, o povo possui saberes provenientes da cultura popular transmitida, oralmente, de pais para filhos, que mesmo não tendo comprovação científica, servem para ajudar na cura das pessoas que deles se utilizam. Isto nos ajuda a compreender a intertextualidade que existe entre o saber popular e o saber científico em determinadas áreas do conhecimento.

O texto "Doenças pneumológicas" explica como acontece a contaminação, como curá-las e como se prevenir por meio da vacinação. $\mathrm{Na}$ opinião dos neoleitores, a facilidade de contaminação deve-se também à questão da alimentação: Hoje, as pessoas se alimentam muito mal, alimentação fraca, comida com conservantes. Muito importante o texto porque nos mostra como tratar a saúde; ficamos sabendo como nos proteger, conhecendo os tipos de doenças pneumocócicas.

Noutra sessão, estudamos uma poesia, intitulada "Mãe", de nossa autoria. O Dia das Mães estava próximo. Foi uma leitura que contou com muita participação. O tema emocionou a todos os presentes, mulheres e homens. Leram com entusiasmo e depois todos participaram de uma dinâmica de fixação da leitura e da escrita. Uma equipe da TV UNIFOR estava presente e fez uma matéria sobre o projeto e a oficina de leitura.

Outro tema estudado foi o "Mosquito do Dengue". Expusemos um banner com doze itens que orientam como cuidar da água e evitar que o mosquito se reproduza em objetos que juntam água da chuva. $\mathrm{O}$ debate envolveu os cuidados que se deve ter com o meio ambiente. Essa discussão foi muito proveitosa, pois todos mostraram preocupação com as notícias dadas pela TV sobre o aquecimento global, o desmatamento das florestas, a poluição dos mares e dos rios, os prejuízos que o lixo mal cuidado acarreta para a saúde da população, etc. O debate foi concluído com a reflexão de um dos participantes: Falta conscientização. Há muita desvalorização das pessoas com as coisas e com a própria natureza. É como se sua geração não tivesse continuidade, através de filhos, netos, bisnetos e demais 
descendentes. Devemos pensar no futuro e não somente no presente. O individualismo de muitas pessoas é triste!

O texto "As dermatoses ocupacionais e sua prevenção" foi estudado por meio de uma dinâmica que envolveu todos os participantes. No final, foram distribuídas cópias do texto com os neoleitores que levaram para suas casas, com a incumbência de lerem com outras pessoas da comunidade.

\section{Perspectivas de continuidade}

O projeto está em andamento, apresentando resultados positivos quanto à assiduidade, participação, desenvolvimento da reflexão crítica, aperfeiçoamento e uso da leitura em situações reais da vida cotidiana. Por enquanto, portanto, não falaremos de conclusão e sim de perspectivas de continuidade.

A leitura de textos informativos organiza o neoleitor para fazer uso do conhecimento formal no mundo que o cerca, abrindo sua compreensẩo para as relações sociais que são criadas entre as pessoas da comunidade, ao mesmo tempo em que o orienta quanto aos cuidados pessoais com a saúde, com o meio ambiente, com a convivência familiar e comunitária, direitós e deveres do cidadão.

As oficinas de leitura têm como característica a participação dos neoleitores em todo o processo, oferecendo-nos a oportunidade de observar, discutir e registrar a aprendizagem e as mudanças de comportamentos em relação ao uso social da leitura. São fontes abundantes de informações e, também, um meio de socialização, de lazer, de reflexão sobre a vida, de leitura do mundo quanto aos problemas comuns e as soluções possíveis para esses problemas, bem como as conquista pessoais e coletivas.

Por meio deste projeto, as pessoas da Comunidade do Dendê vêm recebendo uma grande contribuição no sentido de aperfeiçoar as técnicas de leitura, interpretar textos com informações úteis, criar o hábito de ler entre 
os adultos egressos dos programas de alfabetização, ler conjuntamente com os familiares, amigos e vizinhos, exercitando-se todos para uma convivência harmônica e solidária, em busca de soluções aos problemas atuais que afetam toda a coletividade.

\section{Referências bibliográficas}

ALAMBERT, Z. A mulher na história e a história da mulher. Brasília: Abaré, 2004.

FREIRE, P. A importância do ato de ler. São Paulo: Cortez, 1997.

LEVY, Danielle et al. Responsabilidade social das empresas: A contribuição das universidades. São Paulo: Peirópoles, 2005.

\section{Autora:}

Maria do Socorro Vasconcelos

Doutora em Projeto Curricular e Avaliação Educativa pela Universidad de Valladolid (Espanha). Mestre em Educação de Adultos pela Universidad de Monterrey (México). Licenciada em Pedagogia e Licenciada em Letras pela Universidade Estadual do Ceará. Especialista em Educação não-Formal (CREFAL-México). Especialista em Planejamento do Desenvolvimento Social (Universidade Federal do Ceará). Membro da Academia de Ciências Sociais do Ceará: Cadeira n. ${ }^{\circ}$ 15. Publicou várias obras nas áreas de educação formal e não-formal.

Contato: socorro2000br@yahoo.com.br

Artigo recebido em junho de 2009.

Artigo aprovado para publicação em agosto de 2009. 


\section{Como citar este texto:}

VASCONELOS, M. do S.. O uso social da leitura por meio de textos informativos. Revista Acolhendo a Alfabetização nos Países de Língua Portuguesa, Brasil, São Paulo, volume 1, no. 10, pp. 09 - 22, Mar. 2011. Disponível em: <http://www.acoalfaplp.net>.

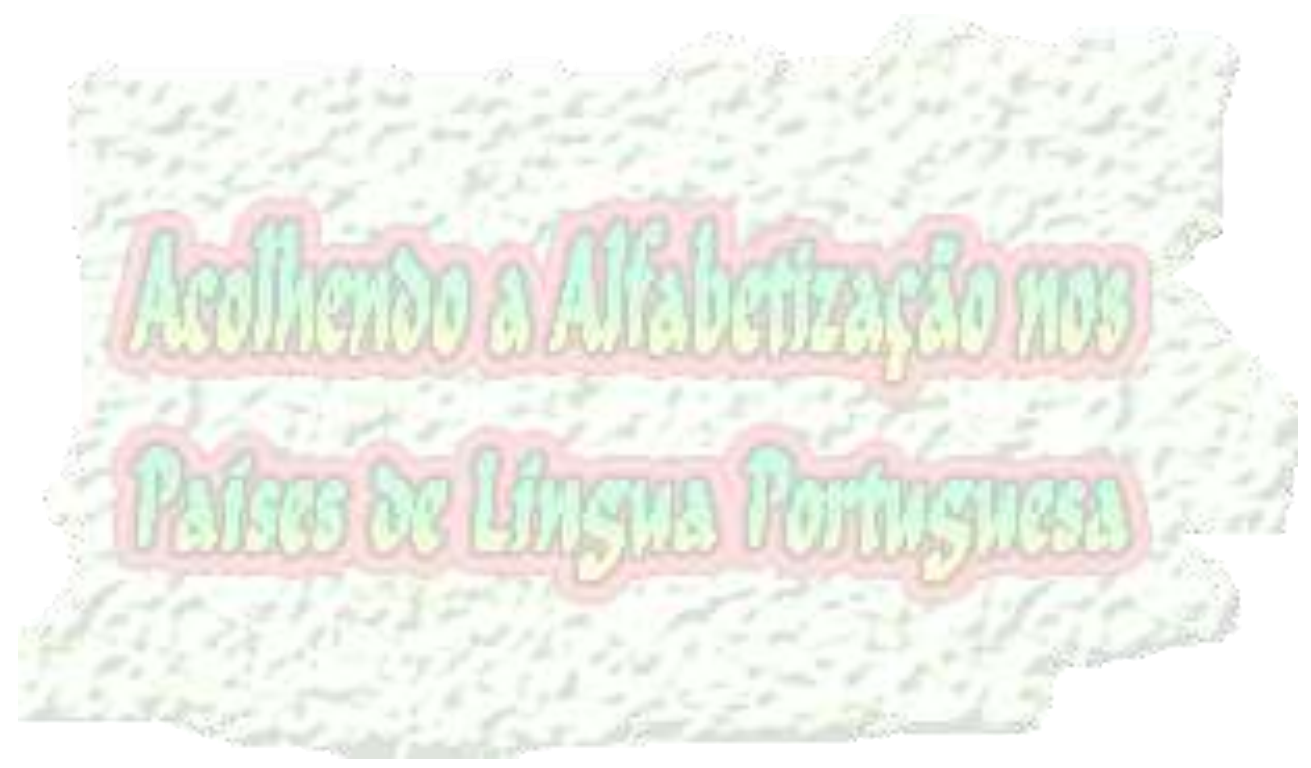

